\title{
O CORPO A CORPO DA E NA ESCRITA
}

Patricia Peterle

Universidade Federal de Santa Catarina - UFSC, Brasil

\begin{abstract}
Resumo
O ensaio busca refletir sobre algumas das problemáticas que incidem no cerne das políticas relativas à pesquisa e à escrita de textos acadêmicos, principalmente, sobre a relação com a escrita, que não deixa de ser uma exposição do sujeito. Tomando como campo de observação o campo literário, a partir de algumas produções de Dante Alighieri, J. L. Borges, Giorgio Caproni, Ana Martins Marques e Giulia Niccolai, pretende-se propor um debate sobre a escrita, que é uma via de mão dupla, que afeta e é afetada por quem a realiza. Os desvios são necessários nos processos de pesquisa e escrita. O divórcio, muitas vezes, imposto pelas amarras do sistema parece, então, gritar diante de algumas marcas e fraturas que, necessariamente, fazem parte e caracterizam a esfera do sensível. O rigor das leituras, dos estudos e das discussões é um dado de extrema relevância, da mesma forma que a linguagem, com a qual um determinado conteúdo é abordado criticamente.
\end{abstract}

Palavras-chave: Escrita; Sujeito; Linguagem.

\begin{abstract}
The essay seeks to reflect on some of the issues that affect the core of policies related to research and the writing of academic texts, mainly the relationship with writing, which is still a part of the subject. Taking as a field of observation the literary field and, from some productions by Dante Alighiei, J. L. Borges, Giorgio Caproni, Ana Martins Marques and Giulia Niccolai, we intend to propose a debate on writing, which is a two-way street, affecting and being affected by those who carry it out. Deviations are necessary in the research and writing processes. The divorce, often imposed by the bonds of the system, seems to scream, in the face of some marks and fractures thatare part necessarily and characterize the sphere of the sensitive. The accuracy of the readings, studies and discussions is extremely important data, just as the language, with which a given content is critically approached, is also so.
\end{abstract}

Keywords: Writing; Subject; Language. 


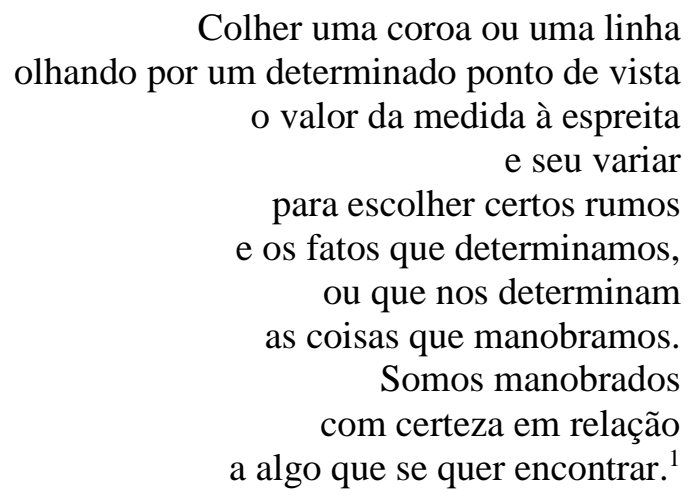

\section{Primeiros questionamentos}

Como se dá a relação com o objeto de pesquisa? Como tal relação é construída? Ela oferece a possibilidade de transformação do pesquisador? Ou ainda pode se pensar na transformação do olhar do pesquisador para seu objeto, eleito como corpus da investigação? Tal objeto também olha para o pesquisador? Sem dúvida, esses elos que vão sendo criados e fortalecidos durante a pesquisa acadêmica e científica fazem parte de todo um processo que só acontece em seu se dar, ou seja, na medida em que ele se realiza. Nesse sentido, seria possível fazer uma primeira colocação, a de que essa relação é indissociável: de fato, ela também é fruto das horas de pesquisa, leituras, reflexões acerca do corpus e daquilo que está a seu redor. Continuando nessa linha, outro aspecto já pode ser antecipado: as imbricações entre escrita e objeto são elas também indissociáveis, uma adentra o outro, numa mescla inevitável cuja urdidura exige tom, ritmo, pausas; enfim, uma complexa trama, que é fruto justamente desse corpo a corpo que a pesquisa demanda.

Em As pessoas e as coisas, livro que retoma e dialoga com as Palavras e as coisas de Michel Foucault, Roberto Esposito traz uma reflexão sobre a separação que "parece organizar a experiência humana desde seus primórdios [...]. O mundo da vida resulta cortado por um divisor de águas que o separa em duas zonas, definidas por sua oposição recíproca: ou se está do lado de cá, entre as pessoas, ou do lado de lá, entre as coisas" (2016, pp. 1-2). O livro de Esposito não trata diretamente da pesquisa acadêmica, mas sim do estar no mundo, das relações entre as categorias de pessoas e coisas, cuja definição também depende de um tempo, da organização da sociedade, enfim, varia de época para época. Uma distinção primária entre pessoas e coisas, da qual também parte o filósofo italiano, é a racionalidade, a saber, o cogito ergo sum cartesiano. Todavia tal divisão desconsidera os elos e, sobretudo, as relações e laços que vão sendo tramados e que, por sua vez, acabam por transformar uma situação inicialmente dada. ${ }^{2}$ Tal divisão, bem como outras, não leva em consideração o "conteúdo corpóreo" 3 de ambas as categorias, que necessariamente aflora a partir do contato e da necessidade da nietzscheana "leitura lenta" evocada por Carlo Ginzburg na primeira parte da entrevista "As más coisas novas", quando o historiador reflete sobre as novas condições e modalidades da pesquisa e do ensino (2020, p. 120). ${ }^{4}$ Essa discussão por si só já abre um 
relevante ponto de questionamento e de discussão, que poderia ser expresso nas seguintes indagações: de que forma tratamos o objeto a ser pesquisado, sobre o qual nos debruçamos?; será esse objeto, esse corpus, realmente uma "coisa" que não diz nada, cabendo ao pesquisador imprimir-lhe um significado, uma leitura?

Gostaria de refletir sobre essas problemáticas que incidem no cerne das políticas relativas à pesquisa e à escrita de textos acadêmicos partindo de meu campo de atuação que é o da crítica literária, o literário. Forma disforme, matéria imaterial, orgânico inorgânico, a literatura é assim um espaço plural, do ruinoso, do contato, do contágio e, sobretudo, do afeto - ao mesmo tempo em que também sinaliza para as tensões ali presentes. $\mathrm{O}$ divórcio, muitas vezes imposto pelas amarras do sistema, parece aqui gritar, uma vez que as marcas que fazem parte e caracterizam a esfera do sensível - afeições e percepções - correm o risco de ficar "congeladas", separadas da escrita que discorre sobre essa mesma esfera. A "leitura lenta" tão importante na visão de Ginzburg, inclusive como elemento fundamental de pesquisa e método, não existe sem um corpo a corpo, sem a ideia da página em branco, que paradoxalmente não é nunca totalmente branca.

Um famoso conto de Borges inicia assim:

Recordo-me dele (eu não tenho o direito de pronunciar esse verbo sagrado, só um homem na Terra teve esse direito e esse homem morreu) segurando uma sóbria flor-da-paixão, vendo-a como ninguém a viu, ainda que a olhasse do crepúsculo do dia até o da noite, por toda uma vida inteira. Recordo-me dele, a cara de índio taciturna e singularmente remota, atrás do cigarro. Recordo (creio) suas mãos afiladas de trançador. Recordo, perto daquelas mãos [...]. Recordo claramente a voz dele; a voz pausada ressentida e nasal do suburbano antigo, sem os sibilos italianos de agora [...]. Minha primeira lembrança de Funes é muito nítida (BORGES, p. 2007, pp. 99-100, grifo meu).

Nesse trecho de "Funes, o memorioso" o que é exposto é um verdadeiro corpo a corpo. O primeiro termo "Recordo-me" indica que se está no plano pantanoso e lacunar da memória, que é trazida por meio de outro campo também lacunoso que é o da linguagem. A experiência de ter conhecido esse alguém, só pode ser revivida benjaminianamente mediante os cunículos e as searas da reminiscência, que já são por si só uma outra coisa. A repetição e a posição anafórica do verbo "recordar", conjugado na primeira pessoa, duas vezes na forma passiva e outras duas na forma ativa, expressam a tensão desse gesto de recuperar algo que está perdido, cuja sobrevivência só é possível a partir de uma montagem dos espaços em brancos (também eles cinzentos, residuais). Nesse sentido, chama a atenção a terceira vez em que "recordo" aparece, seguido pelo verbo "creio" posto entre parênteses - como se fosse uma voz outra, um murmúrio -, dando assim vazão, de um lado, ao esforço feito de traçar a imagem de Funes e, do outro, à dúvida se aquela recordação pode ser mesmo ela. Esse embate do narrador, após esse primeiro momento de hesitação, é necessário para que os fragmentos possam ser recompostos, alinhavados resultando assim, como fica expresso na última frase da citação, em "Minha primeira lembrança de Funes é muito nítida". A imagem de Funes, portanto, só vai ficando "nítida" aos poucos, na medida em que o corpo a corpo acontece. 
Todos nós conhecemos a trama desse famoso conto e o traço marcante desse personagem que é irônica e tragicamente apresentado no título por meio do adjetivo "memorioso".

Nós, num relance, percebemos três copos numa mesa; Funes, todos os brotos e cachos e frutos que uma parreira possa conter. Sabia as formas das nuvens austrais do amanhecer do dia 30 de abril de 1882 e podia compará-las na lembrança com os veios de um livro em papel espanhol que ele havia olhado uma única vez e com as linhas de espuma que um remo levantou no rio Negro na véspera da Batalha de Quebrachado. Essas lembranças não eram simples; cada imagem visual estava ligada a sensações musculares, térmicas etc. Podia reconstruir todos os sonhos, todos os entressonhos. Duas ou três vezes tinha reconstituído um dia inteiro; não tinha duvidado nunca, mas cada reconstituição tinha exigido um dia inteiro. Disseme: Eu sozinho tenho mais lembranças que terão tido todos os homens desde que o mundo é mundo. E também: Meu sonho é como a vigília de vocês. E ainda, por volta do amanhecer: Minha memória, senhor, é como um monte de lixo. (BORGES, 2007, pp. 104-105).

Nesse longo trecho, há uma diferença entre o "nós" e Funes, que é dada por aquilo que é explicitado: enquanto sobre uma mesa o "nós" vê três copos provavelmente de vinho, Funes não vê os copos, mas seu olhar os atravessa abrindo uma espécie de voragem, de vórtice. Anacronicamente e numa espécie de movimento arqueológico, Funes em seu torvelinho voraginoso perpassa pelo copo, adentra-o, vai numa espécie de pré-história daquele momento diante da mesa, chegando aos "brotos e cachos e frutos que uma parreira possa conter". Contudo, tal capacidade extraordinária não lhe rendia muitos frutos, aliás, o afligia. A memória de Funes ("o memorioso") era tanta que não lhe permitia parar, não lhe dava nenhuma trégua. Camada sobre camada, uma acumulação atrás da outra que chegava até a sufocá-lo metaforicamente. Uma riqueza sem tamanho, mas que sem um alinhavo, sem uma costura, sem uma tessitura que pudesse permitir articulações se tornava estéril. É, assim, que se pode compreender melhor a parte final e em itálico do fragmento que é a reprodução da fala de Funes: "Minha memória, senhor, é como um monte de lixo". Mas o que falta a Funes, se ele possui uma memória que todos almejariam, inclusive um pesquisador? Essa resposta é dada ao final do conto pelo próprio narrador, falta-lhe a capacidade de articulação: "Suspeito, contudo, que não fosse muito capaz de pensar. Pensar é esquecer diferenças, é generalizar, abstrair. No mundo entulhado de Funes não havia senão detalhes, quase imediatos." (BORGES, 2007, p. 108). A figura de Funes, nesse contexto, é emblemática pois traz uma problematização do conhecimento e de sua articulação. O elemento ausente é justamente a posição do sujeito diante do vivido. Em outro momento do conto de Borges:

Não só lhes custava compreender que o símbolo genérico cachorro abrangesse tantos indivíduos dispares de diversos tamanhos e diversa forma; incomodava-o que o cachorro das três horas e catorze minutos (visto de perfil) tivesse o mesmo nome que o cachorro das três e quinze (visto de frente) (BORGES, 2007, p. 107). 
Aqui é colocada a questão saussuriana da langue/parole, que vai na direção justamente do ponto tocado anteriormente, o da necessidade de abstração que o pensamento exige. Outro ponto que retorna é o da relação com aquilo que está ao nosso redor. Funes parece ser atropelado pela quantidade de lembranças, por todos os detalhes que ocupam sua mente e que não lhe dão respiro. Ele, enquanto sujeito, não as organiza, não as seleciona, são elas que o abarrotam. Voltando à reflexão do Roberto Esposito, entre pessoas e coisas, aos poucos, vai se estabelecendo um vínculo, que vai deixando suas marcas: "Aquelas coisas trazem as marcas das nossas mãos, o sinal dos nossos olhares, o perfil da nossa experiência [...] nelas se estratificam significados irredutíveis ao plano cognitivo. É o laço simbólico em que sua vida se entrelaça com a nossa. Tal como são os corpos a conferir vida às coisas, do mesmo modo elas os moldam" (ESPOSITO, 2016, p. 106). Esse contato com o fora parece ser, então, mais intenso do que estar ausente e não faz parte do cotidiano do personagem de Borges ("Resolveu reduzir cada uma das jornadas pretéritas a umas setenta mil lembranças, que logo definiria por cifras", BORGES, 2007, p. 107).

\section{Deslocamentos necessários}

É do encontro entre artista e matéria que os objetos chamados de artísticos ganham forma e "vida". A matéria-prima, seja ela qual for - madeira, ferro, argila, palavra, papel - sofre um processo, se modifica para gerar algo que antes não existia. Todavia, o que era antes não é totalmente apagado ou descartado, mas assume uma forma outra. Lendo alguns dos ensaios críticos, muito perspicazes, de Giorgio Caproni, que marcou a poesia italiana da segunda metade do século XX, é possível dizer que: "A poesia é, enfim, um meio de conhecer e de refletir, e nesse imbricado processo a palavra vai se despojando do sinal, símbolo convencionado, que a levaria a um preciso percurso, ao mesmo tempo que a 'pronúncia' das palavras (o som), a cada vez, pode reinventá-las, tocando e acordando a memória, sempre com um timbre diferente, mesmo podendo parecer sempre as mesmas" (PETERLE, 2017, p. 28). Mas que "meio" é esse? Certamente, como toda arte, a poesia coloca em questão a relação entre orientação e desorientação, o deslocamento; de fato, a linguagem dita poética não pode ser a mesma da comunicação comum e cotidiana. É bem verdade que a poesia ao longo do século XX sofre inúmeras transformações, da hibridação e revisitação das formas fechadas ao acolhimento de termos que até então eram vistos como não bem quistos na considerada "boa poesia". Ou seja, a escrita do poema, como afirma Eugenio Montale em um artigo publicado no Corriere della Sera em 1964, se torna mais “inclusiva”. Se o próprio fazer artístico sofre grandes abalos, ao longo do chamado século da barbárie, como ficam as pesquisas e o discurso crítico e acadêmico que se debruça sobre um corpus que desconcerta, descarrilha? Essa é, com efeito, uma questão central de ontem e de hoje.

"A poesia é a ação integral da disposição ao sentido" (2016, p. 149), diz Jean-Luc Nancy em "Fazer, a poesia". Não é uma produção de significações, mas se coloca nesse "meio" em que a disposição ao sentido é essencial, por isso "sua finição é a perfeita atualidade do sentido infinito" (2016, p. 150). Tanto a escrita quanto a leitura de poesia implicam o ser-na-língua. 
As palavras

As palavras. É certo.

Dissolvem o objeto.

Como a névoa as árvores,

o riacho: a barcaça. (CAPRONI, 2011, p. 235)

Nesses versos de $O$ franco caçador (1982), a poesia se dá a ver como "meio" reflexivo (há um cruzamento de pensamento e poesia), colocando indagações, inclusive mediante o silêncio, e focando num tema que é central no século XX. A palavra, matéria-prima do poema, da escrita, é colocada em relação direta com a "névoa", por meio da símile. Quatro versos e dois dísticos apontam para outra operação de suspensão, desta vez relativa à linguagem. A palavra que a princípio deveria dar corpo ao objeto, nomeando-o, colocandoo em uma definição ou significação partilhada pelos falantes, na verdade, ao estabelecer essa ligação referencial, o "dissolve", blanchotianamente, o "mata". Todo o poema é montado a partir de um paralelismo palavra-névoa. A palavra dissolve o objeto, a névoa com seu efeito visual faz com que as coisas que estão presentes numa determinada paisagem possam "desaparecer", provocando incertezas e dúvidas. Tal relação corroborada pelo "como" no primeiro verso da segunda estrofe, é reproposta numa fórmula ainda mais enxuta e seca no último verso: "o riacho: a barcaça" (a costura entre os termos acontece por meio da pontuação, numa operação marcada pelo signo do negativo). Nesse sentido, barcaça e riacho apresentam uma equação análoga às de palavra-objeto e névoa-árvores; com efeito, no riacho, ao longe e com o fluir das águas, a barcaça pode assumir outras feições. "É abandonada qualquer hipótese de nomeação adâmica ou do tipo fiat lux. Estamos no avesso do tecido [na urdidura carcomida da linguagem] - rasgos, feridas, desfiaduras, remendos da visão tradicional de linguagem" (TESTA, 2018, p.13). A linguagem aqui parece dar em si mesma um nó, pois o ato de nomear adamicamente não corresponde a um conhecimento, ou seja, à capacidade de nomear não implica conhecer. Caproni nesse poema e em outros consegue encenar poeticamente algumas reflexões que já o acompanhavam desde o final da década de 1940, como confirmam alguns de seus ensaios. ${ }^{5}$ As palavras não existem isoladamente, elas fazem parte de uma complexa rede de conexões e articulações que age sobre elas e vice-versa. Há uma resistência da poesia.

Por coincidência, em textos em que tratam do tema da tradução, tanto Walter Benjamin ${ }^{6}$ (2010) quanto Giorgio Caproni ${ }^{7}$ (2017) elegem para pensar algumas dessas relações a palavra "pão", em italiano "pane", em alemão "brot", em francês "pain" em inglês "bread". Sem dúvida alguma, é possível afirmar que todas essas palavras, nas diferentes línguas, se referem a um mesmo objeto, feito basicamente de água, farinha e fermento. Contudo, para além desse objeto que é comestível e faz parte da cultura humana há milênios, cada rede de conexões a saber, cada cultura - deposita nessa mesma palavra inúmeras camadas de significações, que 
não precisam ser explicitadas, mas estão ali, fazem parte de uma bagagem da própria palavra (que marca quem a usa, da mesma forma que aquele que a escolhe lhe imprime algo). ${ }^{8}$

É, então, essa fratura que vai chamar a atenção de escritores, poetas, filósofos ao longo do século XX. A linguagem, a língua, às quais até então se creditava todo um poder de nomeação, incluindo também a crença de que por meio dela, da palavra, era possível conhecer e estruturar o mundo, são postas em xeque. Trata-se do "deslocamento sísmico" apontado por George Steiner em sua Gramática da criação. No momento em que a linguagem nomeia algo, já há um deslocamento, um esvaziamento, questão sobre a qual também refletem Blanchot e Foucault, e que está encenada nos versos de Caproni citados acima. Nesse sentido, é possível, agora, também voltar a Funes para perceber que o que está ausente nesse personagem talvez seja também um embate com a experiência (e a experiência com e na língua), sendo ela "outra coisa, porque a experiência em si quando o evento cessa, não existe mais: o que resta são os resíduos que ela deixa como sinal do aconteceu" (PETERLE, 2018, p. 33). Gianni Celati (2011), escritor contemporâneo com passagens pela fotografia e pelo cinema, afirma que a visão de um lugar é como um pensar-imaginar sobre como o mundo é feito e não como um discurso pronto, fechado. A escrita literária, que não deixa de ser um registro, uma tentativa contra o esquecimento (por exemplo Primo Levi), é uma exigência ou necessidade, e ainda a tentativa de adentrar naquela esfera que não conseguimos tocar, que pressentimos, sentimos, tangenciamos, mas não sabemos como "traduzir", aquela "criatura" que fala e ao mesmo tempo "mostra uma forte tendência ao emudecimento", para recuperar as palavras de Paul Celan. E nas palavras de Nancy "'Poesia' é o significante maior do indefinível, do inominável, etc. 'Poesia' compõe sempre uma convocação mais ou menos sub-reptícia à efusão silenciosa” (2016, p. 163)

Vejamos mais dois poemas de Caproni, escritos a partir dos anos 60:

Le carte

Imbrogliare le carte, far perdere la partita.

È questo il compito del poeta?

Lo copo della sua vita?

(CAPRONI, 1998, p. 363, tradução minha)

\section{Geometria}

O importante é mirar

às costas.

Assim forma-se um círculo

onde o perseguido persegue

seu perseguidor.

Donde não se pode mais dizer

(figuras concomitantes

e entre si equidistantes)
As cartas

Trapacear as cartas, fazer com que se perca o jogo.

É essa a tarefa do poeta?

O objetivo de sua vida? 
quem seja o perseguidor

e quem o perseguido.

(CAPRONI, 2011, p. 243)

Versos que provocam deslocamentos em vários níveis (sintático, semântico), acentuados pela cesura e pelo enjambement. Há nessa escrita uma ruptura com certa tradição lírica da poesia, baseada sobretudo na voz de um eu-lírico. De fato, o "eu" não aparece nesses poemas e nem no anterior, "As palavras". Se relermos com atenção esses versos, veremos que eles colocam a nu, expõe e problematizam, o próprio fazer poético (no primeiro, a própria matéria-prima, "a palavra" e sua precariedade; no segundo, o papel do poeta; no terceiro, a sobreposição e confusão dos papéis de perseguido e perseguidor). É talvez nesse sentido que se possa pensar na poesia como um acesso de sentido, por meio também da disposição ao sentido.

Qual é, então, o gesto de Caproni nesses três poemas? Uma sensação em comum entre eles parece ser a da desorientação, dada pelo deslocamento provocado pelo próprio movimentar-se e constituir-se da trama poética. A operação caproniana, seguindo a discussão sobre o "gesto" de Agamben, parece, assim, "tornar visível um meio enquanto tal" (2018, p. 2) e ainda aqui "a medialidade é ativa, porque nela o meio se mostra como tal, no próprio ato em que interrompe sua relação com um fim" (2018, p. 3). Tal interrupção coloca em evidência a suspensão operada; nesse sentido é possível dizer que não há algo a ser comunicado ou um objetivo, na verdade a suspensão está para a abertura de uma comunicabilidade e de uma cognoscibilidade. ${ }^{9}$ A repetição de embaralhar as cartas gera quase uma vertigem, que se expõe ao "explorar, sondar e mostrar todas as possibilidades de que é capaz" (AGAMBEN, 2018, p. 5). Há uma espécie de jogo reverberante entre dito e não-dito, ver e não-ver, que se dá no "ato" de misturar as cartas, o qual também pode estar apontando para outros desvios, descaminhos, inerentes a questões que tocam a posição/constituição do sujeito (perseguido e perseguidor, caçador e preda), a reflexão sobre a linguagem e a crença em seu poder de representação e significação.

O poema "As cartas" traz uma reflexão central sobre a figura do poeta, sobre sua tarefa, seu papel, poder-se-ia dizer, na sociedade, perante os demais, perante a própria língua, o próprio texto. Ele é composto por quatro versos, sendo os últimos dois em forma de pergunta. A imagem inicial reverbera-se nos demais versos por meio da pontuação, a escolha pela pergunta e pelo ponto de interrogação: ela, que a princípio poderia organizar "o embaralhamento", só faz é acentuar esse movimento, cujo ritmo aumenta se considerarmos o fim do poema (AGAMBEN, 2002), com a sinalização do ponto de interrogação. A resposta não dada significaria talvez a perda de todo e qualquer papel, enquanto que a pergunta que paira inscrita no espaço branco da página expõe, a um só tempo, escrita e poeta, potencializando essa mesma relação e suas reverberações, inclusive as éticas. Na mesma linha, o terceiro poema de Giorgio Caproni, "Geometria", mantém a tensão do jogo enigmático ao confundir o leitor: diz sem dizer, fala de um saber, ou melhor não-saber. Nessa "Geometria", que não tem nada de concreto, perseguidor e perseguido, caça e caçador, se alternam a ponto de não se saber mais quem foge e quem corre atrás. Os papéis não são mais 
distinguíveis, são indecidíveis, estão realmente embaralhados. A língua se realiza pelo poema, o poema se realiza na intervenção da língua.

Os exemplos trazidos até aqui abrem feridas na língua, evidenciam seu caráter poroso ${ }^{10}$ e mostram suas possíveis cicatrizes. Afastando-se da ideia de língua como elemento neutro, eles trazem à tona e expõem seu rumorejar e seus balbucios. E a língua torna-se, portanto, um meio, mas em seu se dar, à medida em que tece o relato, lhe dá forma e o transforma. "Essa sonda é a língua, e é na língua que os intervalos e as rupturas que separam o relato e o? fogo mostram-se implacáveis como feridas" (AGAMBEN, 2018, p. 33). Assim, mesmo que a história pareça uma mera ilusão, ela é necessária para tentar penetrar na realidade das coisas, história que também vai se apresentando cada vez mais esgarçada, plasmável como são os personagens, os narradores e as muitas vozes do texto literário. É nessa linha que a língua (inclusive a do pesquisador) não pode deixar de ser um campo de tensões, uma espécie de "batalha" silenciosa e ruinosa em seu próprio interior. É no vacilo, no tropeço, no tremor, que vem à tona e se descobre a potencialidade dos abalos, das cores desbotadas, das sílabas carcomidas, dessa "matéria", que passa por um complexo processo de "aglutinação"; uma relação paradoxal que só se realiza quando se apropria se desapropriando, se desapropria apropriando-se.

Deslocamentos necessários e intrínsecos à poesia, e à arte, que abalam o sujeito, o questionam. Mudando de latitude e olhando para a contemporaneidade, os versos de Ana Martins Marques de "Volapuque"11, título que retoma os versos de Jorge de Sena no poema "Em Creta, com o Minotauro", colaboram ainda mais para essa discussão. O poema de Marques é introduzido por uma epígrafe, composta por dois versos de Jorge de Sena, rastros de uma leitura que possibilita e se abre à escrita que está chegando ("Conversaremos em volapuque, já / que nenhum de nós o sabe."). A primeira coisa a ser dita é em relação a esse termo "volapuque" escolhido pela poeta para seu título. Volapuque, ou "volapük" é uma língua artificial, inventada no final do século XIX pelo padre católico alemão Johan Martin Schleyer. Depois de se questionar e se colocar no papel de inventor de uma língua, o "eu" do poema parece tender para:

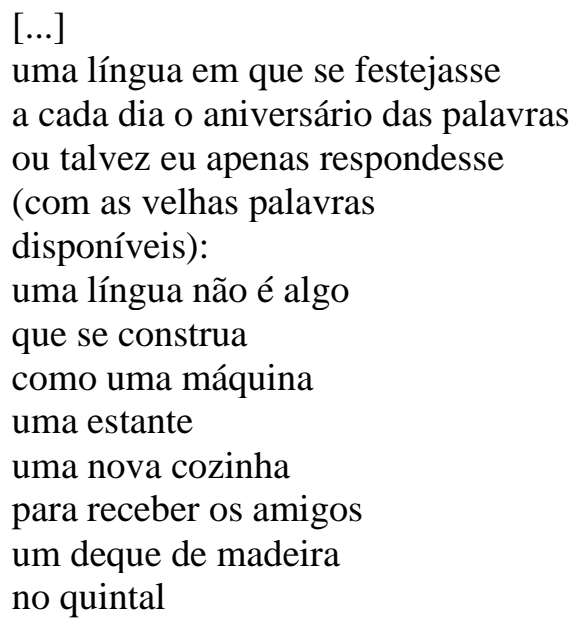


está mais próxima do mar

do que de um barco

é como edificar uma cidade

que por mais que se planeje

sempre haverá

raízes de árvores que crescem

quebrando a calçada

um cachorro que toma para si a porta de uma igreja

uma esquina que já não será a mesma

depois que nela duas pessoas se encontraram

Essas são as duas últimas estrofes das seis que compõem o "Volapuque" de Ana Martins Marques. Na primeira estrofe acima, é colocado que a "a língua não é algo / que se construa", não é uma máquina ou faz parte da esfera daquelas coisas que se podem fazer de forma mais mecânica e, sobretudo, "planejada". Os demais exemplos dados (estante, cozinha, deque) para serem construídos e concretizados precisam de uma organização, de uma sequencialidade que faz parte do planejamento. Um elemento comum a todos esses é, por exemplo, a medida, o metro. É necessário saber o tamanho do espaço para pensar e projetar como eles podem ser construídos. Há, sem dúvida, na realização desses espaços a exigência de um cálculo para que tudo possa estar no devido lugar. Importante notar aqui uma primeira diferença, a estaticidade dos três primeiros espaços diante da maleabilidade introduzida pelo uso do verbo "festejar", que se refere à língua e à palavra. Uma língua não pode ser feita de amarras (regras, gramáticas), por mais que elas existam e sejam necessárias, elas estão ali também para serem trapaceadas, infringidas e suspensas; essa é a festa e a vida das línguas, da experiência da linguagem e de seu ter-lugar. Não é possível conceber o sujeito sem linguagem, da mesma forma que ele a produz e ele mesmo é afetado por ela, para retomar um texto clássico de Émile Benveniste (1991). O homem é um ser de linguagem, mas isso não se dá numa relação unívoca homem-linguagem, há a necessidade de um outro, ou seja, uma relação com o "tu" e, por conseguinte, com o fora.

A segunda estrofe aproxima a língua do mar, essa matéria que escorre pelas mãos, que vemos, identificamos, mas que é inapreensível. Mais uma vez o nome de Giorgio Caproni pode ser trazido a partir do título do "Il mare come materiale" [O mar como material], cujo primeiro verso em grande sintonia com a poeta brasileira diz "Scolpire il mare" [Esculpir o mar]. ${ }^{12}$ Poema da última fase da trajetória de Caproni, pode também ser pensado como uma escultura do preto das letras que parece dançar no espaço da página, e termina da seguinte forma (todo o poema faz uso e joga com os espaçamentos):

Dire

(in calmerìa $\mathrm{o}$ in fortunale)

l'indicibile usando

il mare come materiale...
Dizer

(na calmaria ou no vendaval)

o indizível usando

o mar como material... 
$\begin{array}{ll}\text { Il mare come costruzione... } & \text { o mar como construção... } \\ \text { Il mare come invenzione... } & \text { o mar como invenção... } \\ \text { (CAPRONI, 1998, p. 698, tradução minha) } & \end{array}$

É esse traço do indizível que também está presente nas imagens trazidas por Ana Martins Marques. A aproximação com o mar não é casual, aponta para o traço da forma disforme, da matéria imaterial, que é inerente à linguagem que "manobramos" e também pela qual "somos manobrados", para retomar os versos da epígrafe da artista e poeta Giulia Niccolai. De fato, a imagem do mar, que carrega consigo a acepção de mistério, de profundidade - inclusive de certa ameaça -, é posta nos versos seguintes quando a ideia de planejamento ("edificar") volta no tocante à cidade (nossa outra morada). Todavia, diante de mais uma tentativa de controle, pois planejar também é controlar, nos versos aparece uma irrupção, a das raízes vindas debaixo da terra que violentamente arrebentam a calçada, provocam ruínas, fragmentos que vão necessariamente exigir desvios do passante. Como fica então a língua nesse poema de Ana Martins Marques? Certamente, a poeta descarta a ideia de um planejamento e controle, a festa da língua é dada por seu uso, pela festa que nela é possível fazer com as palavras, pelos contatos e contágios que podem ser abertos nesse espaço, pelos acessos que podem ainda ser explorados, para além de qualquer retórica. Não é à toa que o verso final do poema não termina com o verbo "planejar" (ao qual é inerente certa distância, não implica em um envolvimento), mas sim com o verbo "encontrar": "depois que nela duas pessoas se encontraram". O poema exige o outro, a presença desse outro, uma relação que não pode ser totalmente controlada. Talvez seja por isso que a esquina nunca será a mesma. Não se trata de um espaço à la Funes, do qual serão lembrados todos os detalhes e todas as pessoas que por lá passaram, mas é um espaço residual dos encontros e desencontros, cujos rastros só podem ser alinhavados. As duas pessoas que por lá passaram e se encontraram são, agora, também outras. A contingência, o imprevisível, é o que vai deixando seus vestígios no traçado tortuoso que não adere às inúmeras tentativas de planejamento. ${ }^{13}$ Enfim, são todos esses elementos e gestos que vão, no movimento de apropriação e desapropriação, inventando e dando os contornos de uma língua outra, que só se realiza à medida que é colocada em prática, ação que também tem suas consequências para o sujeito. ${ }^{14}$

\section{Dando formas e assumindo outras}

Os versos da epígrafe que abre este ensaio são de Giulia Niccolai (Milão 1934), poeta, escritora fotógrafa italiana, ligada aos movimentos da neovanguarda. Esse poema faz parte de um conjunto de nove textos, escritos entre 1970 e 1972, reunidos sob o título "Dai Novissimi”. Normalmente, é a crítica que toma o texto artístico como referencial, mas no experimento de Niccolai é o texto crítico que serve como ponto de partida e, mais ainda, como fonte. De fato, esses nove poemas são uma montagem que se constrói usurpando e usando as palavras e frases de Alfredo Giuliani (crítico e amigo da poeta) retiradas de seu 
ensaio introdutivo à antologia de poetas I Novissimi (1961), que foi um marco quando lançada. A poesia acolhe e abraça com cortes e remendos o discurso do crítico, desloca-o, apropriando-se dele e transformando-o numa forma outra. Diz Niccolai na epígrafe que se escolhem certos rumos, mas tais eleições, por sua vez, também determinam quem as faz, essa é uma relação de mão dupla. A língua com a qual se escreve, os argumentos tratados falam ao mesmo tempo do sujeito que está e se constitui por meio daquela singular-plural articulação. Niccolai usa um termo que pode causar certa estranheza no plano do poético, o verbo "manobrar", o qual está ligado a uma concretude muito forte, além, é claro, da ideia de certo controle sobre aquilo que se movimenta. Esse termo retorna nos versos finais do poema, agora numa construção passiva do verbo, cuja ação recai sobre o sujeito ("somos manobrados") em relação a algo que se quer encontrar. Para Simone Moschen Rickes, o sujeito "constitui-se ao mesmo tempo em aquele que é agente de uma ação, sujeito de algo, e aquele que é objeto de uma ação, sujeito a algo" (RICKES, 2007). Questão mais do que presente na produção de Niccolai e que retorna em outros momentos de sua escrita, como fica registrado no poema "Il soggetto è il linguaggio", de Sostituzioni [Substituições] (1972), cujos versos finais são: "Il soggetto è dunque il linguaggio / con cui perpertrare una personale violazione" ["O sujeito é então a linguagem / com a qual perpetrar uma violação"], uma vez que para Niccolai ter a linguagem é também um modo de ser.

Se, como diz Giorgio Agamben em $O$ fogo e o relato, "só podemos ter acesso ao mistério por meio de uma história e, todavia (ou, talvez, caberia dizer de fato), a história é aquilo em que o mistério apagou e escondeu seus fogos" (2018, p. 30), há uma aporia intrínseca nesse gesto do escritor, do artista (e porque não do crítico?). Só temos acesso ao mistério por meio da narração, porém esse mesmo contar faz sobreviver o mistério de outras formas, sendo uma delas a partilha com o leitor, que contribui e também introduz sua própria vivência e experiência nesse processo. Uma escrita fala de si.

Se Caproni, como vimos anteriormente, problematiza a linguagem com uma inteligente intervenção na própria linguagem, profanando-a, propondo quase que equações em cesura, Giulia Niccolai, respirando de certa atmosfera vanguardista, propõe algo de análogo a partir de outras coordenadas. Humpty Dumpty (1969) é uma obra que reúne uma série de experimentações, por meio das quais Niccolai começa a indagar e problematizar a natureza e o funcionamento da linguagem. Vejamos "dictionary", em que o jogo de construir e desconstruir, leva um sentido outro. 


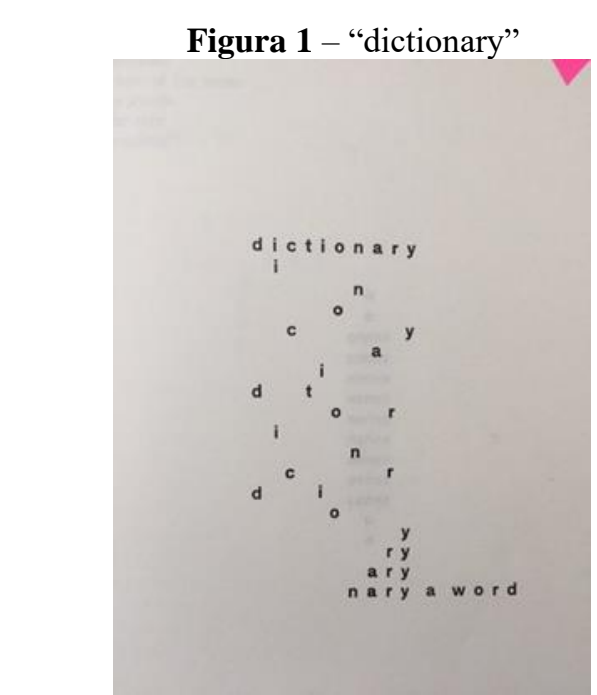

Fonte: (“dictionary”, NICCOLAI, 2012, p. 49)

Na montagem-desmontagem da palavra, cujo significado indica aquele instrumento que todos conhecemos e usamos para buscar o sentido de um termo, a poeta chega ao avesso do "dictionary", por meio de um processo de desmembramento e dispersão silábica. Com os deslocamentos propostos chega-se a "nary", que em inglês clássico é um termo que sublinha o negativo. Nessa operação plástica com a palavra, portanto, chega-se à negação da própria função do termo "dictionary": "nary a word", ou seja, nem mesmo uma palavra, que vai sendo traçado pela geometria visual exposta.

Essa espécie de desorientação é essencial para manter aceso o fogo; é essencial para que a dança sobre o papel branco ou amarelado continue. Por outro lado, esses mesmos poemas dão indícios de algo a mais que os sustenta, a saber, a relação. Colocar a relação em primeiro plano, para além de ser uma questão estética e suas soluções, apresenta-se aqui como algo fundamental: o sentimento da relação como guia, elemento vital para a própria existência, em que as dúvidas não precisam ser resolvidas, mas expostas, em que o fazer artístico é um acontecimento - assim como o pensamento crítico -, e como tal só é possível se realizar por meio de um processo. A alquimia desse fazer-se, desse dar-se, a criação é fruto de uma relação aporética, o autor precisa da obra, mas é também o sem obra - "o homem como o vivente sem obra" (AGAMBEN, 2018, p. 77). É, justamente, essa dança das tensões e relações que também constitui o sujeito, quando de suas manobras e quando ele passa a ser manobrado, como bem coloca Niccolai. Na entrevista de 1968, concedida a Claude Bonnefoy, que também é citada por Agamben, no último capítulo de $O$ fogo e o relato, Michel Foucault afirma que a estada na Suécia foi fundamental para instigar nele próprio algumas questões. Foi uma experiência de estar fora e ao mesmo tempo poder habitar a própria língua de uma outra forma:

Naquela Suécia, onde eu devia falar uma língua que me era estrangeira, compreendi que podia habitar minha língua, com sua fisionomia subitamente 
particular, como sendo o lugar mais secreto, porém mais seguro de minha residência nesse lugar sem lugar que é o país estrangeiro onde nos encontramos (FOUCAULT, 2016, p. 39).

É exatamente nessa situação de deslocamento e desorientação que Foucault constrói o que ele mesmo denomina de "casinha da linguagem". Assim, o prazer da escrita, que vai sendo descoberto pelo filósofo, ganha corpo por meio de uma impotência: "Entre prazer de escrever e possibilidade de falar, existe certa relação de incompatibilidade. Ali onde não é mais possível falar, descobre-se o encanto secreto, difícil, um pouco perigoso de escrever" (FOUCAULT, 2016, p. 39).

Figura 2 - "scultura"

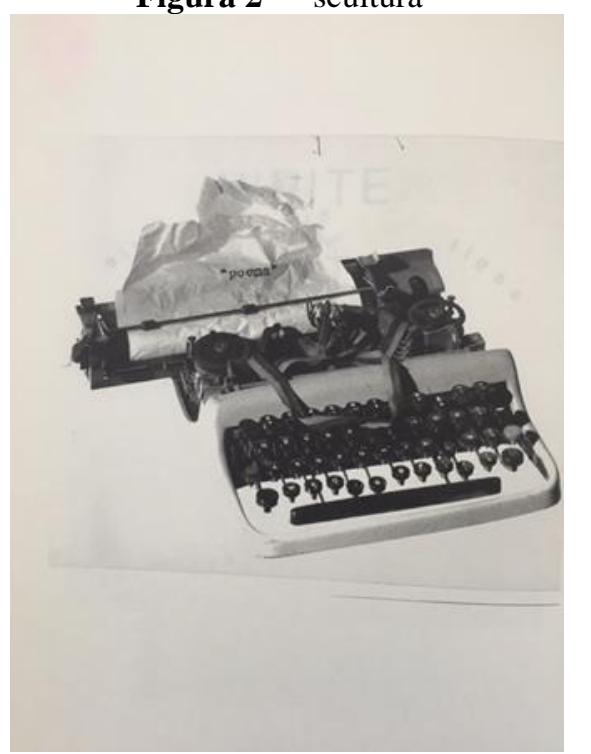

Fonte: (“scultura”, NICCOLAI, 2012, p. 106)

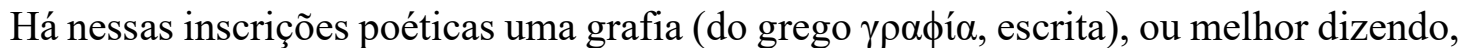
grafias que são indícios do gesto ali presente, que mantém em potência o texto a partir do seu próprio constituir-se e desdobrar-se. Há nesses processos, mesmo considerando todas as diferenças entre eles, um elemento do negativo que os potencializa. Num verso de Vittorio Sereni, de Gli Strumenti umani (1965), ele concretiza essa potência ao dizer que os versos "Escrevem-se só em negativo". ${ }^{15}$ O termo "negativo" aponta sem dúvida para a questão da linguagem acenada anteriormente, central em sua poética, e também na de Ana Martins Marques (o não planejamento, a imagem do mar em sua infinitude e a das raízes arrombando a calçada), Giulia Niccolai e Giorgio Caproni. Contudo, seria também possível pensar em outras conjecturas, como o processo analógico de revelação da película fotográfica em que negativo e positivo, ao se complementarem, oferecem um resultado final, a foto, que só é produzida por meio de um negativo, que é e não é a foto. 
A partir desses passos talvez seja possível lembrar dos versos do Paraíso de Dante, citados ao longo de O fogo e o relato: "o artista / a quem, no hábito da arte, treme a mão", ou na tradução de Cristiano Martins: "como o artista, que a idéia configura, / mas não logra exprimi-la exatamente”. (MARTINS, 1991, p. 395) A potência não é um a priori da obra, mas acontece com ela, a acompanha: à medida em que a obra (podemos também pensar na pesquisa) se constitui - como nos exemplos acima - ela se retorce, passa a ter movimentações não previstas, encontra uma resistência para realizar-se, findar-se. Retorna aqui a suspensão, a operação que inopera, como a mão do artista afetada pelo tremor que interrompe o movimento usual, ou talvez, até esperado. Essa espécie de vórtice, turbilhão parece apontar para uma "poética da inoperosidade" (a figura de Bartleby de Melville, recuperada por Celati e outros escritores, é emblemática). E quando se trata da linguagem, a poesia é aquela operação que desativa as funções pragmáticas, comunicativas, informativas, proporcionando novos rearranjos e combinações - uma espécie de partitura musical: são os timbres citados no início desse ensaio por meio leitura de Giorgio Caproni. A língua deixa de ser utilitária e passar a ser o cerne em que dizer e pensar se tencionam e seguem tecendo. Há, portanto, uma operação da língua na língua, do pensamento no pensamento.

Os textos, as tessituras e as tramas trazidas nessa reflexão parecem ter como material de trabalho uma fraqueza. Fraqueza que é colocada no centro do fazer poético e artístico, e ainda no centro da reflexão por Roberto Esposito, quando num recente ensaio trata do "inacabado". Pergunta-se Esposito: "é possível fazer de uma fraqueza uma força, de um grande atraso uma forma de antecipação, de um resto abandonado uma aposta para o porvir?"; continuando, "é uma hipótese, certamente problemática, a ser mantida sob um controle crítico, mas não impossível de ser trabalhada" (2019, p. 3).

Nesse sentido, mesmo considerando as posições niilistas da linguagem e seu caráter funerário e mortificante, ela parece ser - estou seguindo os passos de Enrico Testa em Heróis e figurantes - o "instrumento indispensável na relação entre os homens" e "sobretudo, o veículo - também no horror - da transmissão da memória” (2019, p. 149). ainda que carcomida e esgarçada. Como tratar e abordar uma urdidura tão complexa como essas com um discurso que se apresenta fechado, totalizante e que raramente se abre para dúvidas? Não seria uma incongruência?

\section{Questionamentos que restam}

Toda a trajetória desse percurso, no fundo, aponta para uma epistemologia em que prevalece a parcialidade e, sobretudo a condição de se ouvir a voz do pesquisador. As pesquisas acadêmicas e científicas devem ser "afetadas", "manobradas" pelos caminhos tortuosos que vão sendo descobertos no realizar-se da própria pesquisa, paralelamente ao rigor que é demandado. O pesquisador precisa ter a consciência de que a totalidade sobre aquele determinado "objeto" é uma pretensão ingênua e até uma falácia construída no cerne do próprio campo científico. O pesquisador possui um corpo que se move e se transforma. $\mathrm{O}$ objeto de pesquisa é, sem dúvida, um parceiro, às vezes de longas caminhadas; é um “objeto" 
que tem corpo, que fala - talvez uma língua outra -, e que nos observa. Esse embate, essa intimidade que se vai criando é sempre outra, parcial e singular. Toda pesquisa precisa de um envolvimento do sujeito, que por ela - na relação que vai sendo estabelecida - é modificado. Esse espaço nessas conjecturas, mesmo respeitando no desrespeito as inúmeras normatividades impostas pelos sistemas, é um espaço por excelência de inoperosidades e, logo, político, ético. É fundamental nessa perspectiva não reduzir as problemáticas, mas fazêlas emergir e expô-las. É também um espaço, pode-se dizer, por excelência, da experiência, termo que vinha sendo trazido na composição dessas reflexões. Trata-se, portanto, da experiência de leitura, ou seja do embate com a construção de um significado possível, ato que só pode existir e tomar corpo com a participação do sujeito, o qual ao mesmo tempo em que coloca toda essa engrenagem em movimento também se transforma, se abre. Nesse sentido o olhar da criança, trazido em vários momentos da produção de Walter Benjamin, principalmente em Rua de mão única é uma imagem interessante a ser recuperada no final desse percurso. Num dos fragmentos desse livro, que não deixa de ser fruto de experiências variadas, ele enfatiza a atração da criança em relação aos restos, aos "desperdícios" que sobram de diferentes trabalhos, os da construção, da jardinagem, das tarefas domésticas, da marcenaria ou da costura. Há uma capacidade intrínseca a elas de ver a partir de um outro foco:

Nesses desperdícios reconhecem o rosto que o mundo das coisas volta para elas, precisamente e apenas para elas. Com eles, não imitam as obras dos adultos, antes criam novas e súbitas relações entre materiais de tipos muito diversos, por meio daquilo que, brincando, com eles constroem. Com isso as crianças criam elas mesmas o seu mundo de coisas, um pequeno mundo dentro do grande (BENJAMIN, 2017, p. 17).

Talvez seja exatamente esse "pequeno mundo dentro do grande" um ponto em que poderiam coincidir esses olhares, à primeira vista tão distantes, o do pesquisador e o da criança. É esse gesto, portanto, de tecer, estabelecer, "criar" relações que se coloca em jogo no trabalho do pesquisador. Nesse sentido, seguindo as colocações de Giovanni Pascoli em O menininho: pensamentos sobre a arte, "o estudo deve mais tirar do que acrescentar" e "[...] deve descortinar os artifícios e nos dar naturalidade" (PASCOLI, 2015, p. 51). ${ }^{16}$ Há nessas colocações uma forte presença do mundo dos afetos e dos sentidos, trata-se daquele "particular inadvertido" do qual fala Pascoli nos primeiros anos do século XX, que é capaz de surpreender e de causar desvios. Ou ainda, em outras palavras, como aponta o filósofo Franco Rella, "Pois bem, ali então precisamos chegar nessa escrita, forçando-a, nessa dimensão da escrita, em que, se eu não posso explicar, posso mostrar o que sinto". Há, diz Rella, uma experiência interior da qual não sabemos falar e há também um pensamento que se faz enquanto se escreve, a escrita não é algo de segundo grau" (RELLA, 2020, p. 128). E num livro de Giorgio Agambem dedicado ao método:

Aliás, toda pesquisa nas ciências humanas - e, por conseguinte, também a presente reflexão sobre o método - deveria implicar um cuidado arqueológico, isto é, 
retroceder no próprio percurso até o ponto em que algo ficou obscuro e não tematizado. Só um pensamento que não esconde o próprio não-dito, mas incessantemente o retoma e o desenvolve, pode, eventualmente, pretender a originalidade (AGAMBEN, 2019, p. 8).

Retomando, agora, os versos do Paraíso de Dante, é imprescindível que também existam e façam parte os momentos de balbucio, que a mão que treme, que na técnica tão necessária se abra uma brecha, uma fissura para a contingência, para o inesperado que está presente em toda e qualquer pesquisa (a imagem das raízes tão bem construída no poema de Ana Martins Marques). Por isso que "a faculdade de imaginação é o dom de fazer interpolações no infinitamente pequeno, de inventar para cada intensidade, enquanto algo de extensivo, uma nova e densa plenitude, em suma, de tomar cada imagem como se fosse a do leque fechado que só ao desdobrar-se respira [...]" (BENJAMIN, 2017, p. 38). Assim, é preciso uma atenção ao movimento, mesmo que seja àquele mais imperceptível. Nesse sentido, as linhas sempre retas e paralelas, com início e fim precisos, em algum momento podem se tocar, como o faz Giulia Nicolai:

Figura 3 - "cinque righe per uma composizione musicale"

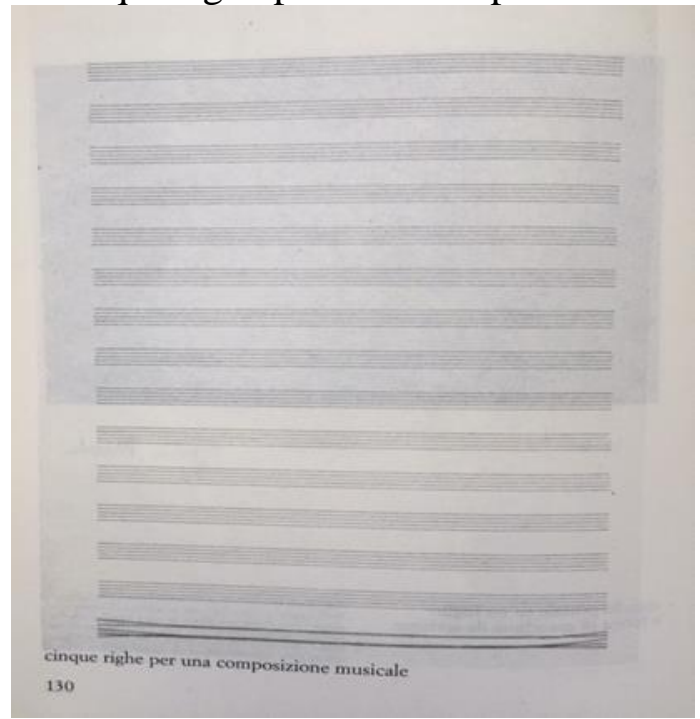

(“cinque righe per uma composizione musicale", NICCOLAI, 2012, p. 139)

A operação de Giulia Niccolai confirma como esses desvios, em outros momentos essas suspensões, sejam necessários, como se dá nessa escrita-imagem reproduzida acima que compõe o livro Poema \& Oggetto (1974). A partitura musical possui uma ordem e uma organização interna: blocos de cinco linhas na horizontal em que essas estão dispostas paralelas e equidistantes. Um código de leitura, uma linguagem que é compartilhada. Uma página em branco com as linhas está pronta para ser preenchida. Mas o que faz Giulia Niccolai? Traz sim a partitura, essa linguagem em sua forma, porém a coloca numa espécie 
de "entre". O último bloco de cinco linhas mantém o paralelismo dos demais, oferecendo, contudo, outra disposição, exposição e execução. Ela suspende com isso o caminho linear esperado, é como se a mão encontrasse outros rumos ou fosse até "manobrada" quando está escrevendo e, ao mesmo tempo, inscrevendo-se. Há um sujeito, sempre parcial e relativo, que se relaciona na intimidade desses textos e por meio dessas conexões se modifica. Tal tensão, se pararmos e prestarmos atenção, não está tão distante do trabalho e da pesquisa crítica e nos remetem à forma e às perguntas colocadas no início desse texto. $\mathrm{O}$ embate e o corpo a corpo do processo de pesquisa e de escrita se dão também por meio desses âmbitos: o de manobrar e o de ser manobrado.

\section{Notas}

1. "Raccogliere una corona o una linea / guardando da un determinato punto di vista / il valore della misura in agguato / e il suo variare / per scegliere certe direzioni / e i fatti che determiniamo, / o che ci determinano, / le cose che manovriamo. / Siamo manovrati / certamente in relazione / con qualcosa che si vuol trovare.", in NICCOLAI, Giulia. Poemi \& Oggetti. Org. Milli Graffi, pref. Stefano Bartezzaghi. Firenze: Le Lettere, 2012, p. 93.

2. A esse propósito é interessante fazer referência a um trecho da recente entrevista do historiador Carlo Ginzburg publicada em Krisis - Tempos de Covid-19, em que ele trata justamente de como os "atores" envolvidos num processo de pesquisa podem fazer com que as premissas iniciais sofram alterações: "Mas é possível entabular um diálogo com, digamos, os atores (um diálogo metafórico, no caso dos historiadores; no caso dos antropólogos pode ser também um diálogo físico), em que as perspectivas, as questões "etic" iniciais se nutrem da perspectiva "emic", e, portanto, se estabelece um diálogo e uma correção também das questões iniciais.” (GINZBURG, 2020, 122).

3. Ainda segundo Roberto Esposito: "Que isso coincida com a esfera do corpo, naturalmente sujeito a instintos e paixões, justifica sua exclusão da essencial plenamente humana do homem, mesmo se o que é excluído, por ser estranho ao binômio entre pessoa e coisa, é precisamente o elemento que permite o trânsito de uma para outra. Como puderam, então, inteiras gerações de homens reduzir outros seres humanos ao estado de coisas, a não ser sujeitando integralmente seus corpos à própria vontade?” (2016, p. 6).

4. Essa entrevista faz parte de um projeto mais amplo que teve como resultado a produção de 50 vídeos e de um livro. O material em vídeo relativo ao projeto Krisis-Tempos de Covid-19, está disponível em: https://repositorio.ufsc.br/handle/123456789/209667 . Acesso em: 08/07/2020.

5. Esses ensaios estão traduzidos no volume já citado A porta morgana (CAPRONI, 2017).

6. Nas palavras de Benjamin: “ Em 'Brot' e 'Pain' o visado é o mesmo; mas o modo de visar, ao contrario, não o é. Está implícito, pois, no modo de visar, o fato de que ambas as palavras significam algo diferente para um alemão e um frnaces, respectivamente; que, para eles, elas não são intercambiáveis e que, alias, em última instância, almejem excluir-se mutuamente; quanto ao objeto visado, porém, tomadas em termos absolutos, elas significam a mesma e idêntica coisa" (2010, p. 213).

7. Além dessa diferença, Caproni irá ainda afirmar: "[...] em poesia, uma palavra assume, além de seu significado lexical, um imprevisível número de significados que eu gostaria de comparar aos 'harmônicos' de uma nota musical, e todos despontados não somente do valor da palavra em si, mas junto com o lugar que ela ocupa na tessitura harmônica do poema" (2017, p. 238).

8. Interessante notar que essa rede cultural e significante, justamente a partir da palavra "pão", está no filme documentário Tradurre. Direção de Pier Paolo Giarolo. Itália. Jolefilm, 2007, 56 min. 
9. Ainda no ensaio de Agamben dedicado ao gesto, na esteira de Walter Benjamin, lê-se: "no gesto o homem não comunica um escopo ou um significado mais ou menos cifrado, mas sua própria essência linguística, a pura comunicabilidade daquele ato liberado de todo o fim. No gesto não se conhece algo, mas apenas uma cognoscibilidade" (2018, p. 3).

10. Sobre a porosidade na poesia, faço referência à disciplina "Pensamento e Poesia: porosidades e sensações" oferecida junto ao Programa de Pós-Graduação em Literatura da UFSC, em 2016.1, cujo programa esta disponível em https://literatura.posgrad.ufsc.br/disciplinas/quadro-de-horarios/2016-2/ . Acesso $11 / 08 / 2020$.

11. Tive contato com esse poema recentemente, quando foi lido na Oficina de Poesia, ministrada pelo poeta Carlito Azevedo, pela editora 7Letras, em 10/08/2020.

12. Sobre esses temas em Caproni, ver PETERLE, 2015, pp. 51-66.

13. Pode ser lembrado, aqui, o sinuoso movimento da enguia, animal a quem Eugenio Montale dedica um poema. Os volteios do animal que também deve superar os obstaculos que vai encontrando em seu caminho se tornam um recomeço, um desvio, enfim, uma abertura. Cf. PETERLE, Patricia, "No vortice dell'anguilla de Eugenio Montale" (2020a).

14. A pesquisa de Doutorado Escrita, morte-vida: Diários com Lúcio Cardoso de Rosi Bergamaschi Chraim (2019), defendida junto ao Programa de Pós-graduação em Literatura da Universidade Federal de Santa Catarina, posteriormente publicada em livro, é uma leitura interessante desses processos.

15. Sobre essa escrita em negativo e a questão do silencio em Vittorio Sereni, faz-se referência a PETERLE $2020 \mathrm{~b}$.

16. Tais colocações também poderiam ser lidas a partir do ensaio "La decadencia del analfabetismo" do espanhol José Bergamín.

\section{Referências}

AGAMBEN, Giorgio. Notas sobre o gesto. Trad. Vinícius Honesko Nicastro. Cardenos de Leitura n.76. Chão da feira, 2018, p. 2.

AGAMBEN, Giorgio. "O fim do poema”. Trad. Sérgio Alcides. In Cacto, 1, ago. 2002.

AGAMBEN, Giorgio. O fogo e o relato. Trad. Patricia Peterle e Andrea Santurbano. São Paulo: Boitempo, 2018, p. 30.

AGAMBEN, Giorgio. Signatura rerum: sobre o método. Trad. Andrea Santurbano, Patricia Peterle. São Paulo: Boitempo, 2019.

BENJAMIN, Walter. "A tarefa do tradutor". In HEIDERMANN, Werner (Org.). Clássicos da Teoria da Tradução. Núcleo de Pesquisa em Literatura e Tradução, 2010.

BENJAMIN, Walter. Rua de mão única. Infância berlinense: 1900. Trad. Joao Barrento. Belo Horizonte: Autentica, 2017.

CAPRONI; Giorgio. A porta morgana: ensaios sobre tradução e poesia. Trad. e introdução Patricia Peterle, Prefácio Enrico Testa. São Paulo: Rafael Copetti Editor, 2017.

CAPRONI, Giorgio. Opera in versi. Org. Luca Zuliani, prefàcio Pier Vincenzo Mengaldo, cronologia Adele Dei. Milano: Mondadori, 1998.

CHRAIM, Rosi Bergamaschi. Escrita, morte-vida: Diários com Lúcio Cardoso. Florianopolois: Nave, Nauemblu Ciéncia \& Arte, 2019.

BERGAMÍN, José. "La decadência del analfabetismo". In La importância del demônio. Madrid: diciones Siruela, 2006.

ESPOSITO, Roberto. As pessoas e as coisas. Trad. Patricia Peterle e Andrea Santurbano. São Paulo: Rafael 
Copetti Editor, 2016.

ESPOSITO, Roberto. Unfinished Italy: paradigmas para um novo pensamento. Trad. Patricia Peterle, Andrea Santurbano. Rafael Copetti Editor, 2019.

FOUCAULT, Michel. O belo perigo, conversa com Claude Bonnefoy. Trad. Fernando Scheib. Belo Horizonte: Autêntica, 2016.

GIULIANI, Alfredo. I Novissimi. Torino: Einaudi, 1961.

ALIGHIERI, Dante. A Divina Comédia. Vol. 2. Trad. Cristiano Martins. Belo Horizonte: Villa Rica, 1991.

NICCOLAI, Giulia. Poemi \& Oggetti. Org. Milli Graffi, pref. Stefano Bartezzaghi. Firenze: Le Lettere, 2012.

PASCOLI, Giovanni. O menininho: pensamentos sobre a arte. Trad. Patricia Peterle. São Paulo: Rafael Copetti Editor, 2015.

PETERLE, Patricia. “Às voltas com Giorgio Caproni”. In CAPRONI; Giorgio. A porta morgana: ensaios sobre tradução e poesia. Trad. e introdução Patricia Peterle, Prefácio Enrico Testa. São Paulo: Rafael Copetti Editor, 2017.

PETERLE, Patricia. "Limites e perigos". In Jornal Rascunho. Disponível em http://rascunho.com.br/limitese-perigos/. Acesso em 9/08/2019.

PETERLE, Patricia. No limite da palavra. Rio de Janeiro: 7Letras, 2015.

PETERLE, Patricia. "No vórtice dell'anguilla de Eugenio Montale". In: Literatura"No vórtice de "L'anguilla" de Eugenio Montale". In Literatura Italiana Traduzida, v.1., n.6, jun. 2020a.Disponível em https://repositorio.ufsc.br/handle/123456789/209670

PETERLE, Patricia. ““'O silêncio criativo”: sobre a poesia de Vittorio Sereni”. In Literatura Italiana Traduzida, v.1., n.7, jul. 2020b.Disponível em https://repositorio.ufsc.br/handle/123456789/209578

PETERLE, Patricia; SANTURBANO, Andrea; DEGANI, Francisco; SALVADOR, Rossana Cristina. Krisis Tempos de Covid-19. Florianópolis: Rafael Copetti Editor, 2020c.

RICKES, Simone Moschen. "Entre a sujeição e o domínio, vibra a posição sujeito: reverberações éticas de uma concepção do sujeito como lugar enunciativo". In Psicol. Soc., Porto Alegre,v. 19,n. 2, p. 15-24, Aug. 2007 Disponível em http://www.scielo.br/scielo.php?script=sci_arttext\&pid=S0102$71822007000200003 \& \operatorname{lng}=e n \& n r m=i s o$. Acesso em 7/08/2020.

TESTA, Enrico. "Vozes trazidas por alguma coisa". In PETERLE, P., SANTURBANO, A. (Orgs.). Resíduos do humano, São Paulo: Rafael Copetti Editor, 2018, p. 13.

TESTA, Enrico. Heróis e figurantes. Trad. Patricia Peterle. Rafael Copetti Editor, 2019, p. 149.

Tradurre. Direção de Pier Paolo Giarolo. Itália. Jolefilm, 2007. 56 min

\section{Correspondência}

Patricia Peterle nasceu em 1974, em São Paulo. É professora de Literatura Italiana na Universidade Federal de Florianópolis, onde também atua no Programa de Pós-Graduação em Literatura. É professora do Programa de Pós-Graduação em Língua, Literatura e Cultura Italianas da Universidade de São Paulo. Pesquisadora do CNPq. Foi palestrante do curso Pensamento Crítico Hoje organizado pelo Centro de Pesquisa e Formação do SESC e pela BOITEMPO, em 2020.Suas áreas de interesse são a literatura do século XX, atuando principalmente nos seguintes eixos: poesia, categorias do contemporâneo, biopolítica, políticas do (in)comum, tradução, com especial atenção para as questões comparatistas. É Editora da revista "Mosaico Italiano" (Rio de Janeiro), junto com Fabio Pierangeli e Andrea Santurbano. Organizou e traduziu edições importantes de Ippolito Nievo, Giovanni Pascoli, Umberto Saba, Enrico Testa, Valerio Magrelli, Eugenio De Signoribus, Giorgio Caproni, Giorgio Agamben e Roberto 
Esposito. Entre seus ensaios ressaltam-se: no limite da palavra: percursos pela poesia italiana (2015); A palavra esgarçada: poesia e pensamento em Giorgio Caproni (2017); Vozes: cinco décadas de poesia italiana (2018).

E-mail: patriciapeterle@gmail.com

Texto publicado em Currículo sem Fronteiras com autorização dos autores. 